\title{
Long-term course of anterior spinal cord herniation presenting with an upper motor neuron syndrome: case report illustrating diagnostic and therapeutic implications
}

\author{
Martin Regensburger ${ }^{1,2,3^{*}}$ (D), Johannes C. M. Schlachetzki ${ }^{1}$, Jörg Klekamp ${ }^{4}$, Arnd Doerfler $^{5}$ and Jürgen Winkler ${ }^{1}$
}

\begin{abstract}
Background: Anterior spinal cord herniation $(\mathrm{aSCH})$ is a rare cause of myelopathy which may present as pure motor syndrome and mimic other degenerative diseases of the spinal cord. In slowly progressive cases, diagnosis may be impeded by equivocal imaging results and mistaken for evolving upper motor neuron disease. As early imaging studies are lacking, we aimed to provide a detailed description of imaging and neurophysiology findings in a patient with aSCH, focusing on the early symptomatic stages.
\end{abstract}

Case presentation: We here present the case of a 51-year old male patient with an episode of pain in the right trunk and a normal spinal MRI. After a symptom-free interval of 8 years, spasticity and paresis evolved in the right leg. There was subtle ventral displacement and posterior indentation of the thoracic spinal cord on MRI which, in retrospect, was missed as an early sign of aSCH. After another 3 years, symptoms spread to the left leg and a sensory deficit of the trunk became evident. Follow-up MRI now clearly showed an aSCH. Neurosurgical intervention consisted of remobilization of the herniated spinal cord and patch closure of the dura defect. Over the following years, motor and sensory symptoms partially improved.

Conclusions: The history of this patient with aSCH illustrates the importance of careful longitudinal clinical follow-up with repeated imaging studies in progressive upper motor neuron syndromes. Specific attention should be paid to a history of truncal pain and to MRI findings of a ventrally displaced spinal cord. Neurosurgical intervention may halt the progression of herniation.

Keywords: Spinal cord herniation, Evoked potentials, Spasticity, Case Report

\section{Background}

In early stages of slowly progressive spasticity of the legs, establishing a diagnosis may be challenging as symptoms are often limited to just one region. The diagnosis of motor neuron diseases like amyotrophic lateral sclerosis (ALS), hereditary spastic paraplegia and primary lateral sclerosis

\footnotetext{
* Correspondence: martin.regensburger@uk-erlangen.de

'Department of Molecular Neurology, University Hospital Erlangen, Schwabachanlage 6, 91054 Erlangen, Germany

${ }^{2}$ Center for Rare Diseases Erlangen (ZSEER), University Hospital Erlangen, Erlangen, Germany

Full list of author information is available at the end of the article
}

relies on the exclusion of spinal stenosis and inflammatory diseases of the central nervous system. This clinical scenario is reflected by the category "clinically possible ALS" according to the El Escorial criteria, defined by clinical evidence of upper and lower motor neuron dysfunction in one region only [1]. Patterns and time course of progression of motor neuron diseases show a considerable variation and cannot be sufficiently predicted to date [2]. Thus, while early diagnosis is an important prerequisite to initiate the correct type of treatment (e.g., riluzole, immunomodulation or surgery), slowly progressive upper motor neuron

C C The Author(s). 2020 Open Access This article is licensed under a Creative Commons Attribution 4.0 International License, which permits use, sharing, adaptation, distribution and reproduction in any medium or format, as long as you give appropriate credit to the original author(s) and the source, provide a link to the Creative Commons licence, and indicate if changes were made. The images or other third party material in this article are included in the article's Creative Commons licence, unless indicated otherwise in a credit line to the material. If material is not included in the article's Creative Commons licence and your intended use is not permitted by statutory regulation or exceeds the permitted use, you will need to obtain permission directly from the copyright holder. To view a copy of this licence, visit http://creativecommons.org/licenses/by/4.0/ The Creative Commons Public Domain Dedication waiver (http://creativecommons.org/publicdomain/zero/1.0/) applies to the data made available in this article, unless otherwise stated in a credit line to the data. 
syndromes may remain unresolved during initial follow-up [3]. Moreover, clear-cut clinical signs or progression markers of upper motor neuron dysfunction are often lacking [4].

We herein report the case of a male patient with thoracic anterior spinal cord herniation $(\mathrm{aSCH})$ who initially presented with monomelic spasticity and weakness leading to a suspected diagnosis of motor neuron disease.
With a comprehensive demonstration of the long-term course of MRI and motor/ sensory evoked potentials, we provide a detailed description of potential early indications for this rare mimic of motor neuron disease.

\section{Case presentation}

A 51-year-old patient presented in 2004 with pain of the right side of the trunk. Neurological examination and

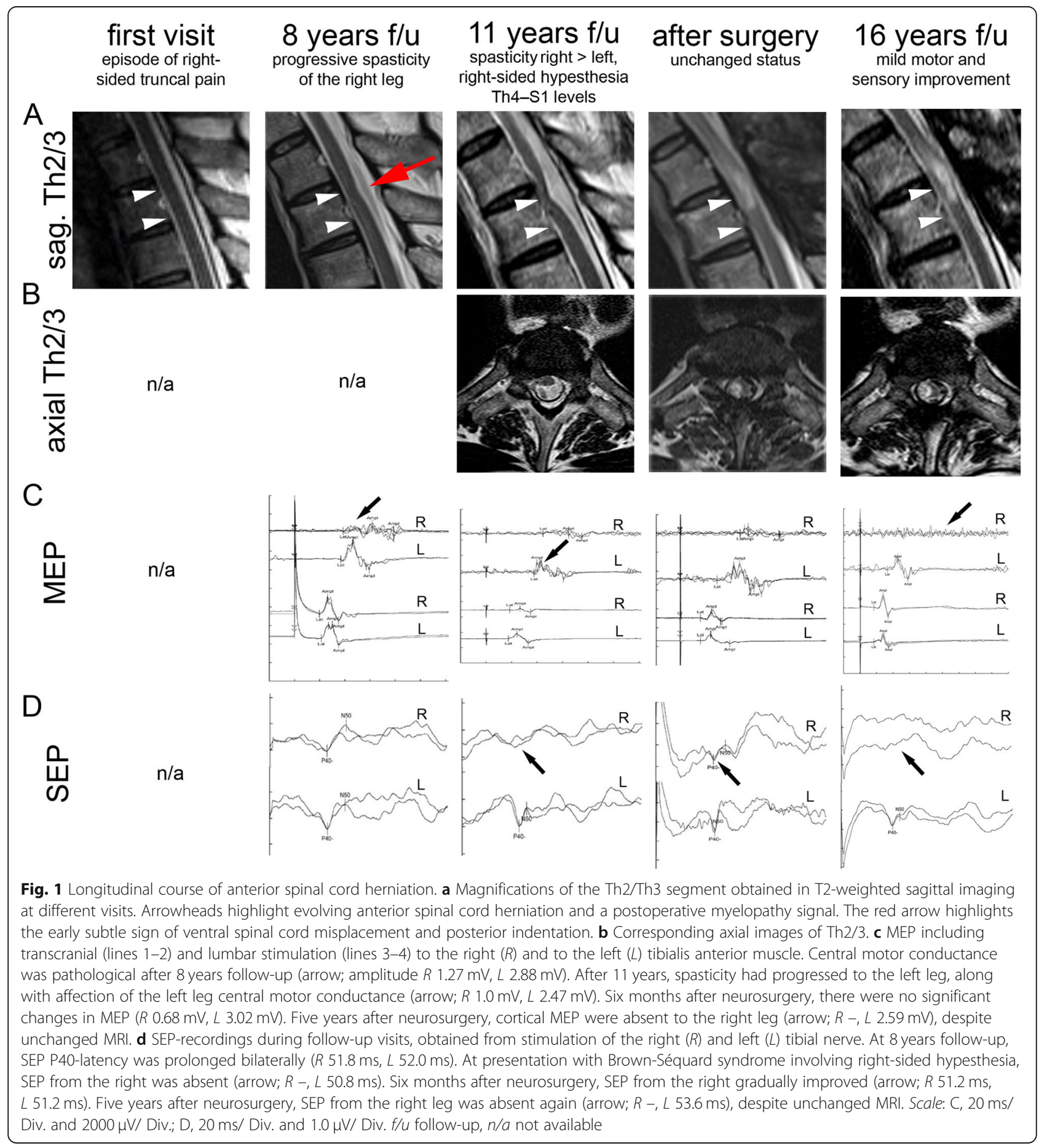


spinal MRI (Fig. 1a) were normal. Symptoms resolved over a course of several weeks after physiotherapy and analgesics. Eight years later, in 2012, the patient developed progressive spastic paresis of the right leg, associated with a positive Babinski sign. Spinal MRI showed a lumbar disk protrusion bilaterally contacting S1 nerve roots, but was otherwise reported normal (Fig. 1a). Motor evoked potentials (MEP, Fig. 1c) indicated central motor conductance pathology to the right leg only. Somatosensory evoked potentials (SEP, Fig. 1d) were normal. Electromyography revealed fasciculations and chronic neurogenic changes in muscles innervated by nerve roots $\mathrm{L} 4-\mathrm{S} 1$ on the right side. Cerebrospinal fluid analysis was unremarkable. Accordingly, we diagnosed a degenerative upper motor neuron syndrome. Due to denervation patterns in EMG readings, differential diagnosis included early stages of ALS; furthermore, spastic paraplegia and primary lateral sclerosis were considered.

Three years later, right-sided hypesthesia involving dermatomes Th4-S1 emerged subacutely, now matching with a Brown-Séquard syndrome. Follow-up spinal MRI showed an aSCH at Th2/3 (Fig. 1a-b). In retrospect, subtle signs of aSCH were already detectable in 2012: The spinal cord was ventrally displaced, appeared attached to the ventral dura and showed a posterior indentation at Th2/3 (Fig. 1a, red arrow). Due to the chronically progressive motor and sensory deficits, neurosurgery was performed. The neurosurgical treatment aimed at relocating the spinal cord into its normal intradural position with closure of the ventral dural defect to prevent reherniation. To gain sufficient access, the spinal cord was mobilized on the right side by applying sutures to the dentate ligaments (Fig. 2a). Part of the herniated cord could be lifted out of

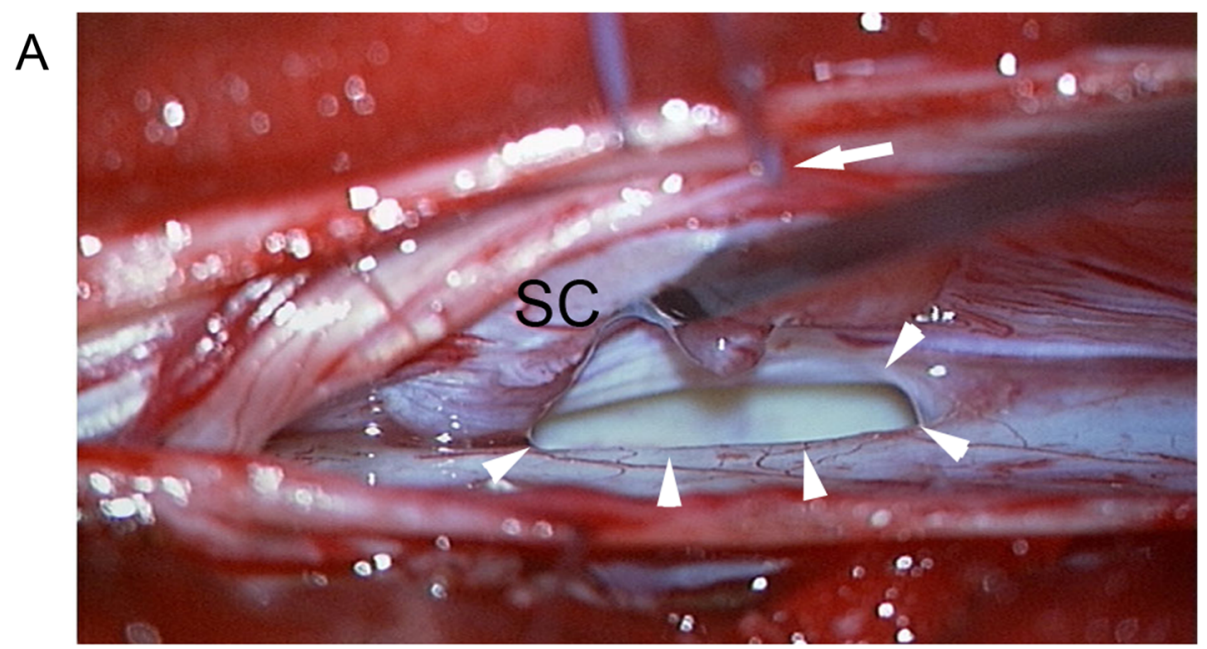

B

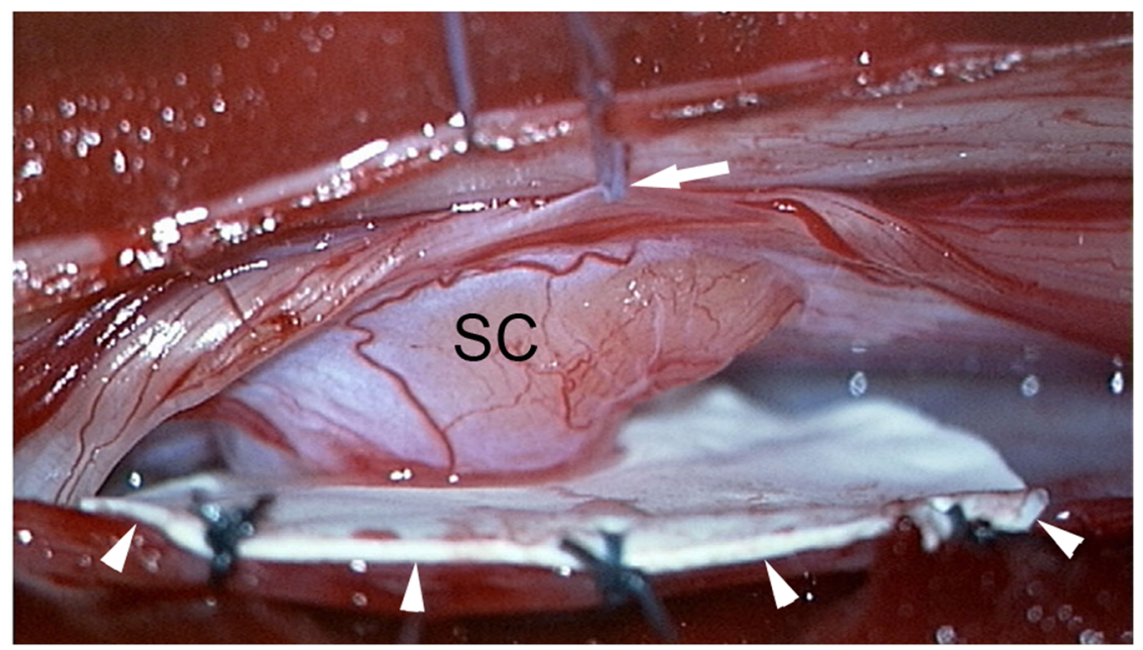

Fig. 2 Intraoperative images. The intraoperative images demonstrate the defect in the anterior dural sac (arrowheads in a) after gently mobilizing the spinal cord with a suture applied to the dentate ligament (arrows in $\mathbf{a}$ and $\mathbf{b}$ ) and closure of the defect with a dura patch (arrowheads in $\mathbf{b}$ ). The herniated part of the spinal cord appears dysplastic (SC in B). SC spinal cord 
the defect easily, while the caudal part required sharp dissection before it could be mobilized. Finally, the defect was closed by muscle and fibrin glue. To prevent adhesions between cord and the closed dura defect, a goretexpatch was placed to cover the former defect (Fig. 2b). During surgery, SEP and MEP were monitored [5]. Postoperative MRI confirmed the corrected position of the spinal cord in the dural sac, and showed profound intramedullary signal changes consistent with a myelopathy at the level of former herniation (Fig. 1b). Six months after surgery, amplitudes and latencies of MEP were unchanged, whereas SEP was slightly improved (Fig. 1c, d). Clinically, symptoms improved partially over the course of 5 years after surgery. Spasticity of both legs was decreased (reduction of the modified Ashworth score of adductors from 2 to 1 on both sides) and the maximum walking distance was increased from 500 to $2000 \mathrm{~m}$. The sensory deficit improved, but persisted in the right trunk (dermatomes Th2-L1). At the latest follow-up in 2020, the patient reported recurring stiffness and pain of both legs probably related to cessation of physical therapy due to COVID-19 pandemic restrictions. Interestingly, while MRI showed no signs of progression at this point, MEP correlated with the clinical increase in spasticity (Fig. 1c, d).

\section{Discussion and Conclusions}

ASCH is a rare cause of myelopathy which may be missed on imaging during early stages of the disease [6].
Whereas Brown-Séquard syndrome is initially observed in the majority of aSCH cases, about $20 \%$ present with pure motor symptoms accompanied by spasticity and paresis of one or both legs [6]. In retrospect, specific signs merit attention as early indicators of a symptomatic spinal cause of lower limb spasticity: (i) Although the patient exhibited an isolated motor syndrome without sensory symptoms, the history of lateralized pain of the trunk should prompt the careful revision of MRI. (ii) Ventral displacement and posterior indentation of the spinal cord on the sagittal plane are indicative for aSCH and should trigger additional axial imaging (Fig. 1a, red arrow).

In the patient presented, coexisting multisegmental lumbar radiculopathy caused additional lower motor neuron pathology. Consequently, an early stage of motor neuron disease (ALS) could not be excluded at this point. SEP were prolonged bilaterally in this patient, but the finding of pathological SEP is not uncommon in ALS and did not preclude a diagnosis of ALS [7]. One patient with concomitant ALS and aSCH has been reported previously, but this single case may also have been coincidental and further follow-up of our patient clearly ruled out ALS [8].

So far, there is no widely accepted pathophysiological concept for these ventral dural defects. Degenerative changes, developmental defects, and spinal trauma may predispose to $\mathrm{aSCH}$, but MRI studies prior to symptom

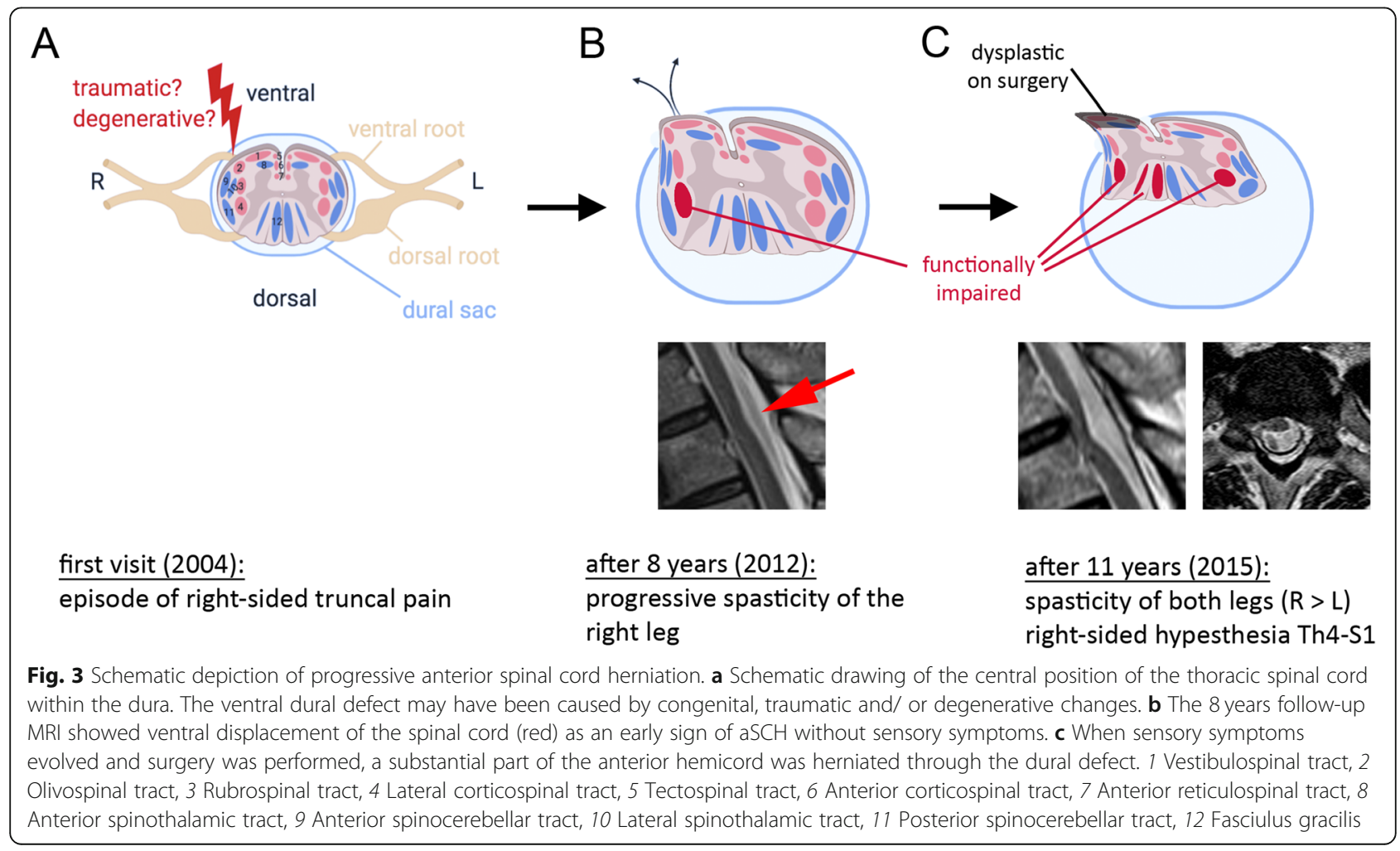


onset are lacking [9]. Our imaging study reveals a gradual herniation of the spinal cord into a dural defect over a course of at least 3 years. The present course suggests that the increasing dural defect was related to degenerative changes. These include small bony spurs or calcified osteochondroses that may cause dural tears leading to larger defects and cord herniation [10]. This view is supported by the fact that the defects tend to be at the level of intervertebral spaces and that large calcified thoracic disc herniations tend to perforate the dura [11-13]. However, degenerative changes of the corresponding disc are not a regular feature in aSCH and were also not observed in the presented patient. It is also not known why aSCH almost exlusively affects the thoracic spine. Therefore, many authors consider these defects as a congenital disposition.

In case, symptoms progress or are associated with a functional impairment, neurosurgical intervention is indicated to halt worsening of the herniation in order to limit the functional deficit. In most cases, functional improvement was reported up to several years after neurosurgical intervention [6]. However, improvement depends on the affected fiber tracts (Fig. 3). Functional impairment is caused by different mechanisms which include pressure/ traction forces, hypoperfusion, secondary swelling, and tissue remodeling [14]. This explains the severe phenotype although only a part of the spinal cord is herniated. Segmental symptoms caused by anterior horn pathology at the Th2/3 level (e.g., intercostal weakness) were not observed, most likely due to the overlapping myotomic organization of the thoracic segments [15].

Postoperative segmental myelopathy, as seen in the presented patient, is commonly observed after spinal cord surgery. It is most likely caused by decompression or loss of traction forces acting on the myelon $[6,16]$. As the myelopathy was stable over several years and there was no spinal cord atrophy, we did not suspect other causes of myelopathy (e.g., inflammatory, neurodegenerative) [17]. Levels of vitamin B12 and folic acid remained within normal limits during the postoperative course.

In summary, our patient illustrates the importance of careful longitudinal follow-up with repeated imaging studies in atypical clinical courses of suspected degenerative upper motor neuron syndromes.

\section{Abbreviations}

ALS: Amyotrophic lateral sclerosis; aSCH: anterior spinal cord herniation; f/u : follow up; L: Left; MEP: Motor evoked potentials; n/a: not available; R: Right; SEP: Sensory evoked potentials; SC: Spinal cord

\section{Acknowledgements}

MR is a fellow of the Clinician Scientist Programme within the Interdisciplinary Center for Clinical Research, University Hospital Erlangen. Figure 3 was compiled with the BioRender.com software.

\section{Authors' contributions}

MR coordinated clinical care and interpreted the patient data. JS performed clinical care. JK performed surgery and provided images. AD performed radiological imaging. JW supervised the study. All authors read and approved the final manuscript.

\section{Funding}

This study was supported by the Deutsche Forschungsgemeinschaft (DFG, German Research Foundation, 270949263/ GRK2162; clinician scientist rotation to MR) and by the German Federal Ministry of Education and Research funded treatHSP consortium (01GM1905B; clinical rotation to MR). Open access funding provided by Projekt DEAL

\section{Availability of data and materials}

All data supporting our findings are presented within Fig. 1. Complete imaging results are upon file with MR and $A D$, and will be shared upon reasonable request.

Ethics approval and consent to participate

As this study was purely retrospective, no ethical approval was obtained.

Consent for publication

Written consent for publication was obtained from the presented patient.

\section{Competing interests}

The authors declare that they have no competing interests.

\section{Author details}

1Department of Molecular Neurology, University Hospital Erlangen, Schwabachanlage 6, 91054 Erlangen, Germany. ${ }^{2}$ Center for Rare Diseases Erlangen (ZSEER), University Hospital Erlangen, Erlangen, Germany. ${ }^{3}$ Department of Stem Cell Biology, University Hospital Erlangen, Erlangen, Germany. ${ }^{4}$ Department of Neurosurgery, Christliches Krankenhaus, Quakenbrück, Germany. ${ }^{5}$ Department of Neuroradiology, University Hospital Erlangen, Erlangen, Germany.

Received: 7 May 2020 Accepted: 16 August 2020

Published online: 29 August 2020

\section{References}

1. de Carvalho M, Dengler R, Eisen A, England JD, Kaji R, Kimura J, et al. Electrodiagnostic criteria for diagnosis of ALS. Clin Neurophysiol. 2008;119: 497-503.

2. Al-Chalabi A, Hardiman O, Kiernan MC, Chiò A, Rix-Brooks B, van den Berg LH. Amyotrophic lateral sclerosis: moving towards a new classification system. Lancet Neurol. 2016;15:1182-94.

3. Jacobson RD, Goutman SA, Callaghan BC. Pearls \& Oy-sters: The importance of atypical features and tracking progression in patients misdiagnosed with ALS. Neurology. 2016;86:e136-9.

4. Swash M, Burke D, Turner MR, Grosskreutz J, Leigh PN, de Carvalho M, et al. Occasional essay: Upper motor neuron syndrome in amyotrophic lateral sclerosis. J Neurol Neurosurg Psychiatry. 2020;91:227.

5. Novak K, Widhalm G, de Camargo AB, Perin N, Jallo G, Knosp E, et al. The value of intraoperative motor evoked potential monitoring during surgical intervention for thoracic idiopathic spinal cord herniation: Clinical article. J Neurosurg Spine. 2012;16:114-26.

6. Sasani M, Ozer AF, Vural M, Sarioglu AC. Idiopathic spinal cord herniation: case report and review of the literature. J Spinal Cord Med. 2009;32:86-94.

7. Georgesco M, Salerno A, Camu W. Somatosensory evoked potentials elicited by stimulation of lower-limb nerves in amyotrophic lateral sclerosis. Electroencephalogr Clin Neurophysiol. 1997;104:333-42.

8. Manara R, Citton V, Nardetto L, Semplicini C, Burlina A, Trevisan C, et al. Spinal cord herniation: a missing piece in the pathogenesis of amyotrophic lateral sclerosis and multiple sclerosis? Neurodegener Dis. 2011;8:381-5.

9. Watters MR, Stears JC, Osborn AG, Turner GE, Burton BS, Lillehei K, et al. Transdural spinal cord herniation: imaging and clinical spectra. AJNR Am J Neuroradiol. 1998;19:1337-44.

10. Klekamp J. A New Classification for Pathologies of Spinal Meninges, Part 1: Dural Cysts, Dissections, and Ectasias. Neurosurgery. 2017;81(1):29-44. 
11. Wortzman G, Tasker RR, Rewcastle NB, Richardson JC, Pearson FG. Spontaneous incarcerated herniation of the spinal cord into a vertebral body: a unique cause of paraplegia: Case report. J Neurosurg. 1974;41:631-5.

12. Brus-Ramer M, Dillon WP. Idiopathic Thoracic Spinal Cord Herniation: Retrospective Analysis Supporting a Mechanism of Diskogenic Dural Injury and Subsequent Tamponade: Fig 1. Am J Neuroradiol. 2011;33:52-6.

13. Kumar N, Fogelson JL, Morris JM, Pichelmann MA. Superficial Siderosis Should Be Included in the Differential Diagnosis of Motor Neuron Disease. Neurologist. 2012;18:139-45.

14. Imagama S, Matsuyama Y, Sakai Y, Nakamura H, Katayama Y, Ito Z, et al. Image classification of idiopathic spinal cord herniation based on symptom severity and surgical outcome: a multicenter study: Clinical article. J Neurosurg Spine. 2009;11:310-9.

15. Wu X, Liu J, Tanadini LG, Lammertse DP, Blight AR, Kramer JLK, et al. Challenges for defining minimal clinically important difference (MCID) after spinal cord injury. Spinal Cord. 2014;53:84-91.

16. Souza RBD, Aguiar GBD, Daniel JW, Veiga JCE. The pathophysiology, classification, treatment, and prognosis of a spontaneous thoracic spinal cord herniation: A case study with literature review. Surg Neurology Int. 2014;5(Suppl 15):S564-6.

17. de Carvalho B, Barros P, Pereira P, Vaz R. Late postoperative myelomalacic myelopathy. Spinal Cord. 2015;53(Suppl 1):S27-9.

\section{Publisher's Note}

Springer Nature remains neutral with regard to jurisdictional claims in published maps and institutional affiliations.

Ready to submit your research? Choose BMC and benefit from:

- fast, convenient online submission

- thorough peer review by experienced researchers in your field

- rapid publication on acceptance

- support for research data, including large and complex data types

- gold Open Access which fosters wider collaboration and increased citations

- maximum visibility for your research: over $100 \mathrm{M}$ website views per year

At BMC, research is always in progress.

Learn more biomedcentral.com/submissions 